\title{
Influence of Acid-Activated Micro-Dispersed Additive on the Properties of Cement Sulphate-Resistant Compositions
}

\author{
Victoria Petropavlovskaya ${ }^{1, a}$, Tatiana Novichenkova ${ }^{1, b^{*}}, K^{2}$ irill Petropavlovskii ${ }^{1, c}$ \\ and Maria Zavadko1,d
}

${ }^{1}$ Tver State Technical University, 22, Af. Nikitin, Tver, 170026, Russia

avictoriapetrop@gmail.com, btanovi.69@mail.ru, craikiri@inbox.ru, d79043517876@yandex.ru

Keywords: Ash, Waste, Activation, Microdispersed Additive, Microspheres, Cement

\begin{abstract}
Research is devoted to the possibility of obtaining a composition based on a microdispersed ash additive and a plasticizer. Waste from sewage sludge ash used. They are formed at thermal power plants. Such ashes are distinguished by the presence of a large amount of organic matter and a low calcium content. Therefore, they are rarely used in construction. The activation of the waste fuel and the use of a plasticizer can improve the performance of cement compositions with the inclusion of sewage sludge ash.
\end{abstract}

\section{Introduction}

Modern approaches to construction production are based on the formation of comfortable conditions for the existence of humans, animals and plants, provided that natural resources and energy are saved. Therefore, the attention of researchers and manufacturers is directed to the involvement of waste in the resource-intensive production of building materials and products. One of such wastes is ash waste from the fuel industry. It is formed when coal is burned. More than 1 billion tons of ash have been accumulated in Russia. It occupies large areas of the urban area and is the cause of environmental pollution [1-9]. Ash can be a source of air and groundwater pollution with heavy metals, which pose a potential threat to the environment even in small quantities $[2,3$, 4].

At the same time, in the construction industry, fuel ash is used as a raw material for cements [8], clinker-free binders, concretes [5-9], the production of porous aggregates, silicate materials, ceramic products, as well as for thermal insulation and other materials $[1,10,11,12,13]$. Ash is also used in compositions for roadway construction, strengthening of soils and foundations. However, not all ashes are used in production, in most cases due to their composition.

Waste fuel can have a different chemical and grain composition. Fly ash consists mainly of highly basic aluminosilicate glass, of several crystalline phases, including quartz, hematite, magnetite, mullite, anhydrite [5], and may contain varying amounts of unburned coal in the form of a coarse fraction (depending on the conditions combustion) and other components [1, 6]. Unburned coal - organic residue can reduce the corrosion resistance of concrete, can swell when interacting with water, have low adhesion with a binder, and can form hazardous compounds. These compounds can destroy the cement stone. The efficient use of fly ash requires the removal of unburned coal and the separation of an aluminosilicate microsphere [6]. Aluminum-containing microstructures - glass-crystalline aluminosilicate balls (microspheres) are the most valuable component in ash [7]. According to the chemical composition of the shell, the microspheres are oxides of silicon and aluminum in combination with small amounts of oxides of iron, calcium, magnesium, sodium, etc. Aluminosilicate granules can participate in the formation of the structure of an artificial stone and contribute to an increase in strength without disturbing the technology of its cementation. 
Dispersion and granulometry of fuel ash are also the most important characteristics [11].

Fly ash as a raw material component of geopolymer binders is responsible for the reactivity in the medium of the alkaline activator and the formation of the optimal pore structure of the composite [11].

The value of fly ash from the standpoint of obtaining aerated concrete composites based on geopolymer binder is in obtaining cheap raw materials. A raw material source in the synthesis of energy-efficient cementless cellular materials can be acidic fly ash [11]. The amount of acidic fly ash in aerated concrete can vary from $15 \%$ to $80 \%$ by weight of the cement. Replacing part of the cement with ash can reduce production costs and improve the environmental situation.

The use of high-calcium ash with a significant content of free $\mathrm{CaO}$ as a component in various cements is hampered by their low durability. This is due to an increase in the volume of lime during its delayed hydration, which leads to the formation of cracks and a decrease in strength $[9,13]$.

The formation of cracks in artificial cement stone using high-calcium ash can be avoided. For this, ash grinding to a higher specific surface area can be used [13]. Additionally, it is proposed to grind ash together with a superplasticizer. In this case, a nanomodified organomineral additive is formed, which has a high homogeneity and chemical activity [14].

Ash, when combined with a superplasticizer, is capable of at the same time reducing the water demand of the concrete mixture [14]. According to K.S. Stenechkina the use of ash-based modifiers reduces delamination, water separation, and also reduces the formation of fine-grained concrete efflorescence [14].

According to S.V. Samchenko $[15,16]$, the use of a superplasticizer can lead to the formation of a large number of crystallization centers and the growth of fine-fibrous or fine-acicular crystals of the ettringite phase. This will contribute to the formation of a dense and durable structure of the future stone $[15,16,17]$. Conditions can be created in the system under which the rate of nucleation exceeds the rate of crystal growth $[15,16]$.

Partial replacement of cement with fly ash reduces heat generation during the hydration of the binder [2], therefore, the risk of cracking of concrete at an early stage is reduced, following this one can consider their use in massive structures, for example, in foundations, platinum used up to $50 \%$ of ash by weight of the binder $[4,9]$.

The durability of concrete is additionally favorably influenced by calcium hydrosilicates. When a nano-modifier based on mechanically activated fly ash is introduced into a multicomponent binder, a greater number of crystals are formed. In a concrete system, an increase in strength and density occurs $[14,18]$. In addition, according to the authors of [1] fly ash has the properties of an independent hydration-hardening binder, which are enhanced by mechano-chemical activation of ash by additional grinding with cement and a setting regulator.

The introduction of up to $50 \%$ fly ash contributes to the preservation of the strength of finegrained concrete $[1,14]$. The introduction of up to $40 \%$ of activated fly ash contributes to an increase in strength up to $50 \%$. The strength of concrete is increased by $30-50 \%$ if a nanomodifier is used. It is an additive of mechanically activated fly ash in the amount of $0.5-1.0 \%$ in combination with a superplasticizer [14]. It is noted that the superplasticizer is able to improve the technological properties of the concrete mixture and the physical and mechanical characteristics of the concrete stone at the same time [10].

However, it is necessary to establish limits for the use of ash in cements and concrete. An increase in the proportion of ash in the binder to $50 \%$ reduces the strength of concrete after heat treatment by 6-7 $\mathrm{MPa}$ [18]. But it is noted that the proportion of replacement of Portland cement with ash does not affect the strength of concrete after 6 months of hardening. Therefore, the 
crushed ash is considered as a slowly hardening binder component. On the other hand, the progress of the reaction with ash depends on the presence of capillary pores where hydrates are precipitated, i.e. the degree of ash reaction is higher in a system with a large amount of water-filled space [19].

Another type of waste is sewage sludge ash.

Such ashes are composed of inhomogeneous particles with a rough surface texture and a porous microstructure. This can lead to high water uptake and increased water demand. For example, in the composition of cement stone and concrete. This was established in [20]. To achieve the desired workability of the mixture with hydro removal ash, a higher water content was required compared to the control mixtures with fly ash. This was expected given the benefits of fly ash on the rheological properties of the mixtures.

In addition to the high organic content of sewage sludge ash, the main oxides are $\mathrm{SiO}_{2}, \mathrm{Al}_{2} \mathrm{O}_{3}$ and $\mathrm{CaO}$. Oxides $\mathrm{Fe}_{2} \mathrm{O}_{3}, \mathrm{Na} 2 \mathrm{O}, \mathrm{MgO}, \mathrm{P}_{2} \mathrm{O}_{5}, \mathrm{SO}_{3}$ and others are present in smaller quantities. The average aluminum content is approximately $14 \%$. This indicates the suitability of such ash for the production of aerated concrete. The high aluminum content of acidic sewage sludge ash can also incr21 ease the resistance of concrete to chloride attack due to the ability of amorphous alumina to bind chlorides.

With a higher content of sewage sludge ash - up to $11 \%$ - the content of heavy metals, sulphates and in particular phosphorus becomes excessively high. This leads to an increase in the setting time and suppression of the development of strength.

The characteristics of such ash, in particular its fineness, suggest that this material may be suitable for use in concrete. Ash is introduced as filler and fine aggregate. Thus, the use of sewage sludge ash led to an increase in strength (up to $70 \%$ ) due to the filling effect from a higher content of fine particles. Despite the increase in the permeability of the resulting mixtures. There is a decrease in the thermal conductivity of concrete due to the porous nature of the organic part of sewage sludge ash [20].

With the dispersion of the hydro removal ash, the area of intergrowth contacts between the particles increases and the transfer of electrons in the surface layer becomes much easier [2, 14]. This is reflected in the change in the performance characteristics of the created material in comparison with the original. Fibrous crystals are observed in the microstructure of ash-cement stone [20]. They "pierce" the pore space of the artificial cement stone, contributing to its strengthening.

When ash is used as an ultradispersed filler, the physical and mechanical characteristics of ashcement stone, ash-cement-sand concrete are improved. At the same time, for ash-cement-sand concrete, the compressive strength increases to $35 \%$, and in bending up to $32.4 \%$. In the case of ash-cement stone, the compressive strength increases up to $30 \%$, and the thermal conductivity decreases by $6.5 \%$. The optimal ratio of ash to cement in this study was 30:70 [21].

Fly ash, hydraulic removal ash - each of them has its own advantages and disadvantages. Therefore, when designing compositions, it is necessary to provide for measures to improve the quality indicators of composites, concretes and solutions based on them.

In this work, we investigated the possibility of obtaining an ash-cement composition based on activated acidic sewage sludge ash to obtain a sulfate-resistant binder.

\section{Materials and methods}

In the studies, the following raw materials were used to obtain ash-cement compositions: sewage sludge ash (fig. 1) - waste from the Kashirskaya SDPP, Moscow Region. Ash dispersion varied from $0 \mu \mathrm{m}$ to $100 \mu \mathrm{m}$; cement - manufacturer "LafargeHolcim" company, Kolomna, Moscow region, standard compressive strength - at least $50 \mathrm{MPa}$; quartz sand was used as a fine aggregate 
(fig. 2) (Tver region). The work also used an organic plasticizing additive - hyperplasticizer (produced in St. Petersburg). In the composition of raw mixtures, the ratio of cement and sand was taken constant - Cement : Sand $=1: 3$. The conditions for varying the components in the composition of the adopted mixtures are shown in Table 1.

Table 1. Composition of mixtures

\begin{tabular}{|c|c|c|c|c|}
\hline \multirow{2}{*}{ № } & \multicolumn{4}{|c|}{ Composition components } \\
\cline { 2 - 5 } composition & Cement & Sand & Ash, $\%$ & Plasticizer, $\%$ \\
\hline 1 & + & + & 5 & 0 \\
\hline 2 & + & + & 15 & 0 \\
\hline 3 & + & + & 5 & 0,2 \\
\hline 4 & + & + & 15 & 0,1 \\
\hline 5 & + & + & 15 & 0,1 \\
\hline 6 & + & + & 10 & 0 \\
\hline 7 & + & + & 10 & 0,2 \\
\hline 8 & + & + & 10 & 0,1 \\
\hline 9 & + & + & & \\
\hline
\end{tabular}

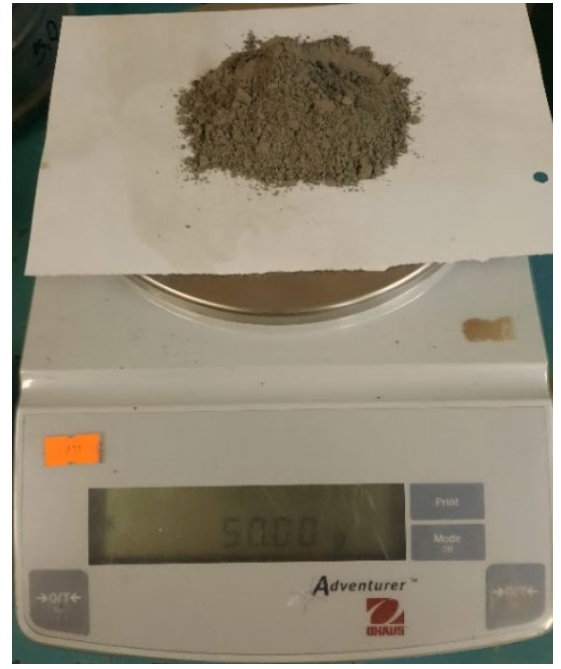

Fig. 1. Sewage sludge ash

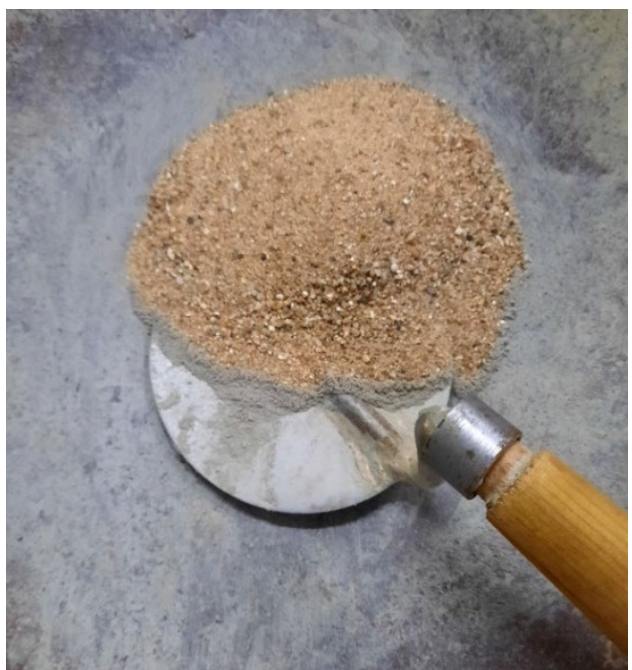

Fig. 2. Quartz sand

Studies of the physical and mechanical characteristics of cement compositions were carried out at the age of 7 days (fig. 3). Compressive strength tests of specimens with natural moisture were carried out on a hydraulic press (fig. 4). 


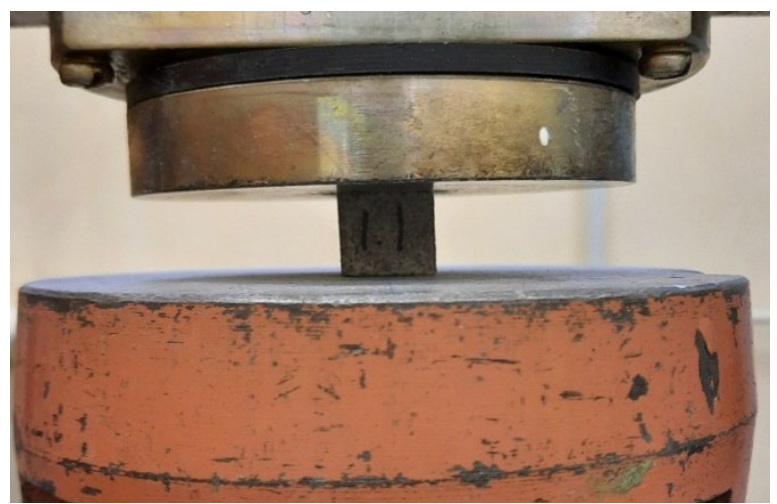

Fig. 3. Testing a sample on a hydraulic press

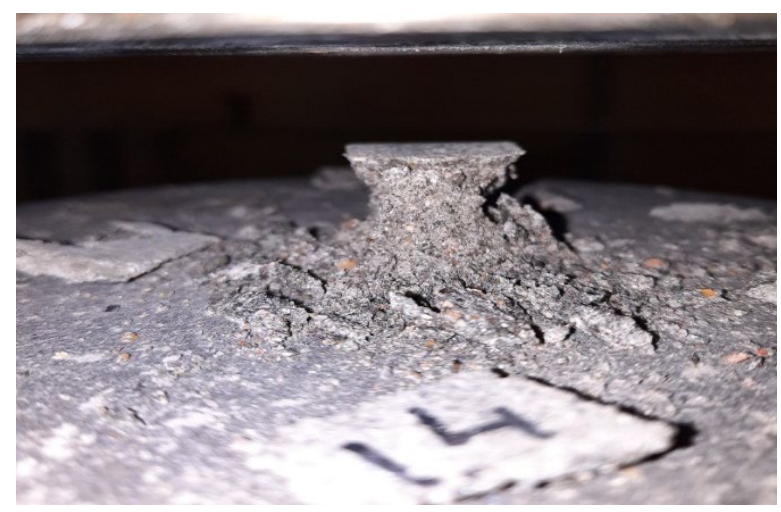

Fig. 4. Fracture of sample

The amount of ash and organic plasticizing additive in table 1 is given as a percentage of the weight of the cement.

To determine the ultimate compressive strength and average density of the cement composition containing a complex additive, standard cubes (fig. 5) were made from mixtures with a normal consistency. All investigated compositions of cement compositions before testing were stored in a chamber with a humidity of at least $90 \%$ at a temperature of $(20 \pm 2){ }^{\circ} \mathrm{C}$ (fig. 6).

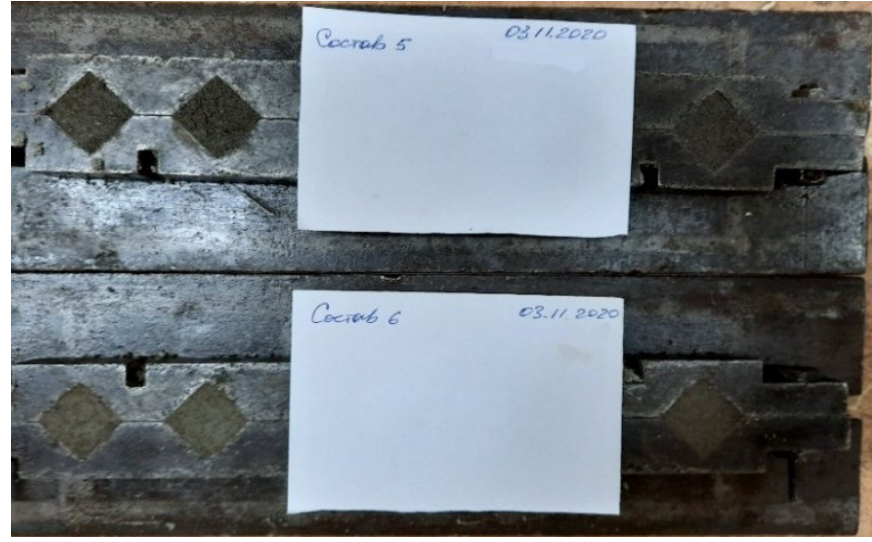

Fig. 5. Sample molding

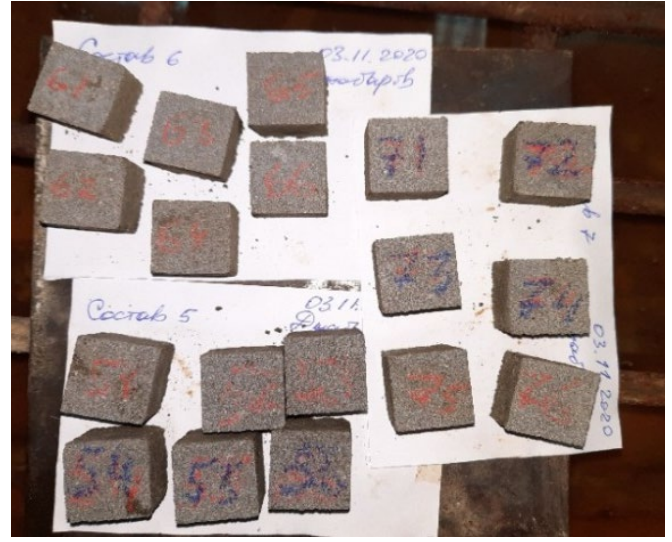

Fig. 6. Samples in the hardening chamber

\section{Results and Discussion}

In order to improve the properties of the ash component, its mechanical activation was carried out. Based on its results, a microdispersed additive was obtained with a wide particle size distribution and a decrease in the average particle diameter in the mixture to $13 \mu \mathrm{m}$.

The results of studies of physical and mechanical characteristics are shown in table 2 .

Table 2. The results of testing the compositions of cement compositions with additives

\begin{tabular}{|c|c|c|c|c|c|c|c|c|c|}
\hline $\begin{array}{c}\text { № } \\
\text { composition }\end{array}$ & 1 & 2 & 3 & 4 & 5 & 6 & 7 & 8 & 9 \\
\hline $\begin{array}{c}\text { Compressive } \\
\text { strength, MPa }\end{array}$ & 15.4 & 17.9 & 22.1 & 14.1 & 22.4 & 24.9 & 22.5 & 21.4 & 20.3 \\
\hline $\begin{array}{c}\text { Density, } \\
\mathrm{kg} / \mathrm{m}^{3}\end{array}$ & 1851 & 1946 & 1963 & 2092 & 2168 & 2186 & 2184 & 2213 & 2184 \\
\hline
\end{tabular}


The effect of the material composition of cement compositions on the compressive strength is shown in fig. 7. The change in the average density of artificial stone depending on the material composition of cement compositions is shown in (fig. 8).

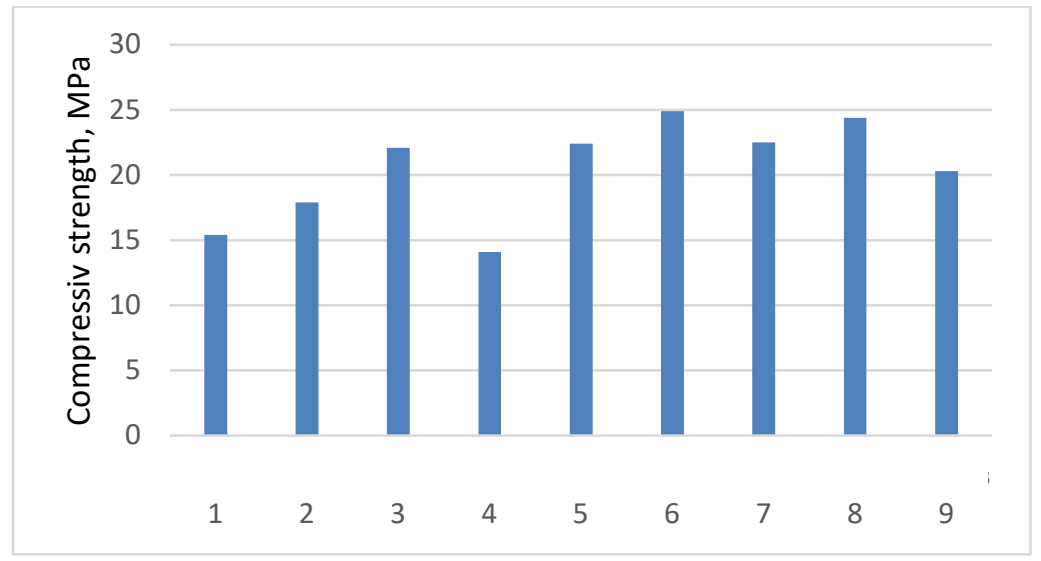

Fig. 7. Compressive strength of cement compositions.

According to the results of density studies, it was found that the average density of the compositions increases with an increase in the content of the ash component. The maximum density value is achieved by adding $10 \%$ ash (composition No. 8). The content of the hyperplasticizer in it was maximum - $0.2 \%$. With the introduction of ash over $10 \%$, the density of the composition decreases monotonically. The minimum density value has been reached for composition No. 1 . The ash content in it was $5 \%$, organic additive $-0 \%$.

The maximum value of the ultimate compressive strength of the samples was obtained for composition No. 6 with an ash content of $15 \%$ and a plasticizer $-0.1 \%$ by weight of cement. The average density of this composition has reached a value of $2186 \mathrm{~kg} / \mathrm{m}^{3}$. The decrease in density relative to the maximum achieved result was less than $1 \%$.

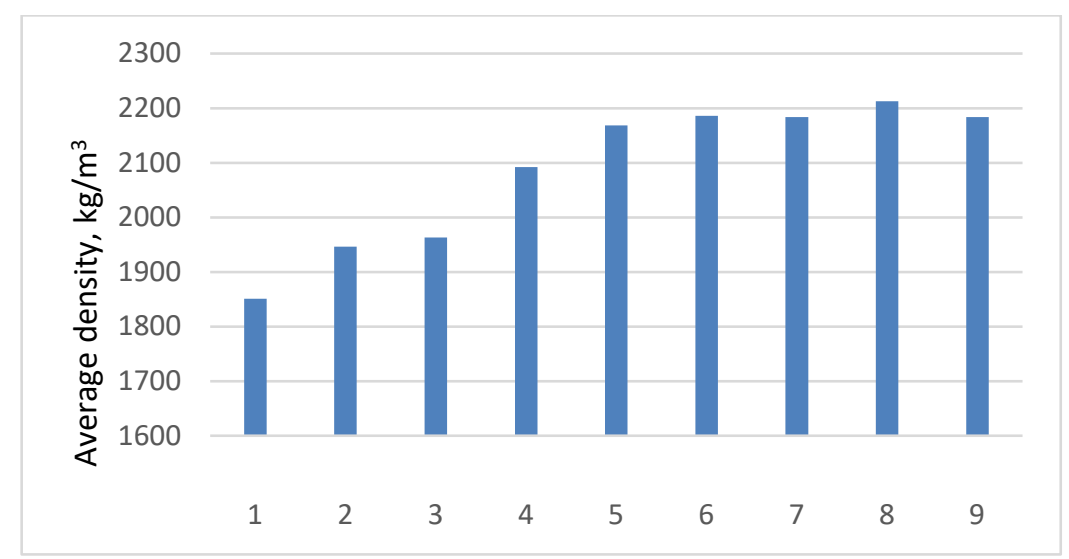

Fig. 8. Average density of cement compositions

Analysis of the conducted studies on the strength and density of cement compositions with the addition of acid ash and a plasticizer showed that the best results were achieved when testing composition No. 8. An increase in strength correlates with an increase in the density of artificial cement stone. This is due to the formation of a stone structure with a dense packing of particles due to the presence of ash particles as a mechanical filler at different structural levels. In addition to compaction, activated ash acts as a physicochemical agent. She participates in physical and chemical transformations in the hardening cement system. This is confirmed by the test results. 
The process of structure formation is activated. The introduction of an active mineral additive in the form of ash accelerates mineral formation. The results of tests of this composition for sulfate resistance for 7 months confirm the high resistance of the cement composition with an activated microdispersed ash additive. Cement stone shows no signs of sulfate corrosion. Research is ongoing. The compressive strength of composition No. 8 on the 7 th day of hardening was 24.4 $\mathrm{MPa}$, the density of the stone was $2213 \mathrm{~kg} / \mathrm{m}^{3}$.

\section{Conclusion}

The analysis of the combined effect of the activated microdispersed additive and the plasticizer on the properties of cement sulfate-resistant compositions showed that the addition of ash and an organic additive can both worsen and improve the performance of cement stone and concrete. The optimum amount of activated ash is $10 \%$ with a plasticizer content of $0.2 \%$.

The results obtained are in good agreement with the results of studies of the effect of mechanical activation of fly ash with a superplasticizer on the properties of the material obtained in [6]. The combined plasticizing effect of ash and organic polycarboxylate component favorably affects the properties of the resulting cement stone. All of its main characteristics are increased. The activation of the ash component allows to improve the structure of the stone, to increase its strength due to the formation of additional structural bonds. The combination of high density and strength relative to other series of samples also predetermines the best operational characteristics of this composition - water absorption, water resistance, frost resistance, etc.

\section{Acknowledgements}

This work was supported by the Russian Science Foundation (project No 21-79-30004).

\section{References}

[1] E.A. Belyakova, R.N. Moskvin, V.S. Belyakova, Ash and slag wastes of CHP and prospects for their disposal, Education and science in the modern world. Innovations 5 (2016) 151-157.

[2] Z.T. Yao, X.S. Ji, P.K. Sarker, J.H. Tang, L.Q. Ge, M.S. Xia, Y.Q. Xi, A comprehensive review on the applications of coal fly ash, Earth-Science Reviews 141(2015) 105-121. https://doi.org/10.1016/j.earscirev.2014.11.016

[3] Kemal Celik, Cagla Meral, A. Petek Gursel, P. Kumar Mehta, Arpad Horvath, Paulo J.M. Monteiro. Mechanical properties, durability, and life-cycle assessment of self-consolidating concrete mixtures made with blended portland cements containing fly ash and limestone powder, Cement \& Concrete Composites 56 (2015) 59-72.

https://doi.org/10.1016/j.cemconcomp.2014.11.003

[4] N.I. Kozhuhova, D.N. Danakin, I.V. ZHernovskij, Features of geopolymer aerated concrete production based on fly ash of Novotroitskaya CHPP, Construction materials 1-2 (2017) 113117.

[5] M.O. Korovkin, V.I. Kalashnikov, N.A. Eroshkina, Effect of high calcium fly ash on the properties of self-compacting concrete, Regional architecture and construction 1(22) (2015) 4953.

[6] K.S. Stenechkina, Organomineral additive based on CHP fly ash, Velez 4-1 (46) (2017) 102-106. 
[7] Ciarán J. Lynn, Ravindra K. Dhir, Gurmel S. Ghataora, Roger P. West, Sewage sludge ash characteristics and potential for use in concrete, Construction and Building Materials 98 (2015) 767-779. https://doi.org/10.1016/j.conbuildmat.2015.08.122

[8] A.F. Kosach, M.A. Rashchupkina, I.N. Kuznecova, M.A. Darulis, Influence of ultradisperse filler based on water removal ash on cement stone properties, Bulletin of Tomsk State University of Architecture and Construction 1(21) (2019) 150-158. https://doi.org/10.31675/1607-1859-2019-21-1-150-158

[9] I.YU. Petrik, V.N. Gubar', S.V. Kornienko, Corrosion resistance of concrete with high content of TPP fly ash, Bulletin of the Donbass National Academy of Construction and Architecture 4 (126) (2017) 103-107.

[10] S.V. Samchenko, E.M. Makarov, Formation and growth of ettringite crystals in the presence of polymeric functional additives, Successes of modern science and education 5(12) (2016) 118-122.

[11] V.P. Kuz'mina, Fillers for dry building mixtures, Dry building mixtures 3 (2017) 8-15.

[12] M.K. Kuderin, K.D. Babiev, Aluminium silicate microsphere in energy saving and energy efficiency of buildings and structures, Science and technology of Kazakhstan 1 (2019) 94-101.

[13] A.Yu. Bashkurov, Selection of optimal composition of lightweight grout for well cementing, Exploration and protection of subsoil 5 (2019) 53-56.

[14] Van Lam Tang, Zoan Nguen, Lam Tung, S.V. Samchenko, Effect of ash and slag waste additive on properties of sulphoaluminate Portland cement, Bulletin Moscow State University of Civil Engineering 8(14) (2019) 991-1003. https://doi.org/10.22227/1997-0935.2019.8.991-1003

[15] Yu.M. Bazhenov, V.V. Voronin, L.A. Alimov, A.M. Bahrah, O.A. Larsen, V.N. Solov'ev, Dyk Vin' Kuang Nguen, High-quality self-compacting concretes using coal combustion waste, Bulletin Moscow State University of Civil Engineering 12 (111) (2017) 1385-1391. https://doi.org/10.22227/1997-0935.2017.12.1385-1391

[16] E. Berodier, K. Scrivener, Evolution of pore structure in blended systems, Cement and Concrete Research 73 (2015) 25-35. https://doi.org/10.1016/j.cemconres.2015.02.025

[17] V.B. Petropavlovskaya, T.B. Novichenkova, A.F. Buryanov, K.S. Petropavlovskii, Selfhardening of a gypsum, Key Engineering Materials 729 (2017) 517. https://doi.org/10.4028/www.scientific.net/KEM.737.517

[18] Xu Gang, Shi Xianming, Characteristics and applications of fly ash as a sustainable construction material: A state-of-the-art review, Resources, Conservation \& Recycling 136 (2018) 95-109. https://doi.org/10.1016/j.resconrec.2018.04.010

[19] R.S. Fedyuk Design of cement composites of increased impermeability, Bulletin Moscow State University of Civil Engineering 5 (2016) 72-81. https://doi.org/10.22227/19970935.2016.5.72-81

[20] Yu.A. Belencov, O.M. Smirnova, D.D. Shamanina, Self-compacting concrete using ground limestone filler, Construction - 2016: Materials of the II Bryansk International Innovation Forum (2016) 22-25.

[21] M.S. Ageeva, S.M. Shapovalov, A.N. Bocman, A.V. Ishchenko, On the use of industrial waste in the production of cementitious substances, Bulletin of Belgorod State Technological University 9 (2016) 58-62. 